\section{Whooping cough in the} United Kingdom 1977-8

SIR,-Professor G T Stewart (9 August, p 451) is nimble both on his feet and in his mind. The great majority of doctors in this country who have worked very hard over the years to control epidemics of communicable disease in childhood have seen their successes reversed by the misguided efforts of people like Professor Stewart, Jack Ashley, MP, and one or two other people.

The toll of misery brought about by such gentlemen has been well recognised by $\mathrm{Dr}$ John Cunningham (a GP in Hildenborough, Kent) writing in World Medicine. ${ }^{1}$ Readers of the Daily Telegraph will be aware that Jack Ashley had the gall to publish a letter recently ${ }^{2}$ expressing his concern for child health and hoping that proper attention would be paid to the report of Mrs Renée Short's committee.

I doubt if I am alone in thinking that those people should be thoroughly ashamed of themselves. The situation will take a long time to retrieve.

T MCL GaLlowaY

Hampshire Area Health Authority,

${ }^{1}$ Cunningham JS. World Medicine 1980;15 (14):10.

- Ashley J, Hannam J. Daily Telegraph 24 July 1980:16.

\section{Poliomyelitis worldwide}

SIR,-As you point out in your leading article (28 June, $p$ 1555) in many Third World countries the incidence of residual paralysis from poliomyelitis is high-it may indeed be nearly $1 \%$ of all children. ${ }^{1}$ The elimination of poliomyelitis and other diseases by use of vaccine is a priority of WHO and the Save the Children Fund. There are certainly difficulties of administration, as you say; but there are other less well-recognised dangers.

The giving of oral polio vaccine or Salk-type inactivated vaccine is exceedingly dangerous unless governments recognise that there can never be any going back. Once the passage of wild virus is interrupted the number of cases will drop: parents and politicians then consider immunisation unnecessary. Even if immunisation rates fall, it may be some years before wild virus circulates; when it does, the number of victims could be greater than if vaccine had never been used. ${ }^{2}$ The reason for this increase would be that the percentage of persons susceptible to paralysis increases with age and at 10 years and above is about 10 times that at 2 years. $^{3}$ Once immunisation against poliomyelitis is begun it must continue.

Therapeutic or prophylactic measures for other ills may increase the incidence of poliomyelitis by increasing the susceptibility of the individual. Thus small children given multiple injections of salvarsan and its derivatives for congenital syphilis have suffered about a $25 \%$ attack rate of paralytic poliomyelitis. ${ }^{4}$ High paralytic attack rates have followed injections for yaws. ${ }^{4}$ An epidemic among small children in a leprosarium, with $24 \%$ cases, may have been provoked by injections of dapsone. ${ }^{4}$ In tropical and subtropical countries the incidence of paralysis in lower limbs only ranges from $75 \%$ to $89 \%$, whereas in temperate countries it ranged from $42 \%$ to $54 \%^{1}$ : injections are given in the lower limbs in tropical countries, more generally in the upper limbs in temperate countries. Large-scale campaigns to inoculate children with diphtheria, pertussis, and tetanus and other vaccines or injections may precipitate paralytic poliomyelitis and discredit preventative medicine. The coincidence of injections followed by paralysis of that limb has been noted by doctors ${ }^{5}$ and parents. ${ }^{6}$ Large-scale use of injected vaccines must be preceded by immunity to poliomyelitis, which may not be easy to achieve. As noted in your leading article, seroconversion after oral polio vaccine may be boosted by repeated doses. Repeated doses, however, entail delay before other injected vaccines can be given, and increase the number of visits to be made and the load on the health services and budget.

We do not know how far the present incidence of poliomyelitis is linked to immunosuppression caused by malaria and malnutrition, to injections given by practitioners of Western and traditional style medicine, and perhaps to other factors. ${ }^{1}$ It is essential that the giving of all vaccines must be carefully and completely monitored.

\section{University Department of Biology,
Bradford BD7 IDP}

H V WyatT

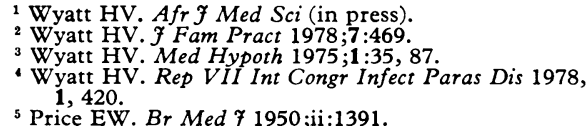
${ }^{5}$ Price EW. Br Med F 1950;ii:1391.

' Nicholas DD, et al, Br Med f 1977 ; : 1009-12.

\section{Outbreak of tuberculosis after} minimal exposure to infection

SIR,-I write to express my concern at some of the comments in the article by Dr V R Rao and others (19 July, $p$ 187) on an outbreak of tuberculosis after minimal exposure to infection. Experience of those of us who work in areas where tuberculosis is rather more common suggests that it is less highly contagious than the authors describe. It may be that with the progressive eradication of the disease we will in future be confronted with as vulnerable a population as apparently is found in Sandwell, but clearly many of us have not yet reached this situation.

More alarming than the comment about the infectivity are the authors' conclusions in so far as they apply to treatment. There is really no evidence to justify their statement that "on detecting a case of respiratory tuberculosis with smear-positive sputum the patient should be isolated in hospital" and that isolation in hospital for two to four weeks is desirable. Indeed, as your admirable leading article (5 April, p 962) pointed out, there is virtually no evidence to support the view that secondary cases can be diminished by hospital admission. The urgent necessity is for diagnosis at the earliest possible moment and prompt effective chemotherapy.

\section{Central Middlesex Hospital,}

MarTin W MCNicol London NW10 7NS

\section{Changing patterns of communicable disease in England and Wales}

SIR,-Dr N S Galbraith and others in their paper on newly recognised diseases in the United Kingdom (9 August, p 427) deal with infection with Giardia lamblia. One of the aspects of transmission which they failed to mention was sexually acquired infection in male homosexuals.
Sexual transmission of intestinal parasites has been recognised in New York for several years. ${ }^{12}$ Kean et al ${ }^{2}$ examined the stools of 126 sexually active homosexual men in New York, of whom $40 \%$ had $G$ lamblia or Entamoeba histolytica, or both. The authors estimated that up to 50000 people in New York may be infected with these parasites.

Recently two cases of "sexually acquired" amoebiasis were described in the United Kingdom. ${ }^{3}$ Neither patient had travelled abroad during the preceding eight years and both were homosexual males. Several cases of giardiasis in homosexual men have been seen at the Middlesex Hospital in the last few months. The last case was a man who presented with abdominal pain and diarrhoea. There was no recent history of travel abroad and stool microscopy revealed cysts of $G$ lamblia.

Transmission appears to be faecal-oral, usually by oral-anal contact. ${ }^{4}$ In the United

States the practice of inserting a hand or even a forearm into the partner's rectum is not uncommon, ${ }^{5}$ and such practices must result in gross faecal contamination. I am sure that in the next few years, intestinal parasites will be increasingly recognised in the male homosexual population in the United Kingdom.

A Mindel

Academic Department of Genito-Urinary Medicine, Middlesex Hospital Medical School,

London W IN 8AA

Schmerin MJ, Jones TC, Klein H. Ann Int Med 1978;

88:801-3.
Kean BH, William DC, Luminais SK. Br f Vener Dis 1979;55:375-8.

Public Health Services Laboratory. Communicable Disease Report 1980;CDR 80/31.

1977 5 53:54-5. Karic HA, Holmes KK. Brf Vener Di $1977,53: 54-5$. 478-84.

\section{Distalgesic poisoning-cause for concern}

SIR,-We are sorry that Mr P S Dwyer and Dr I F Jones (5 July, p 60) have been unable to understand the analysis presented in our paper (12 April, $p$ 1045) on poisoning by Distalgesic (dextropropoxyphene and paracetamol). We wish to allay some misconceptions that may have arisen from the contents of their letter.

Far from attempting to conceal the fact that the majority of deaths from overdosage occur outside hospital, we again confirmed this in our paper by the figures presented. Thus in the three and a half years for which full hospital and community data were available there were nine deaths outside hospital and four in hospital. Eight of the 13 deaths were due to Distalgesic and only three due to barbiturate. These are the bare facts.

Our further calculations were designed to show that the majority of patients taking 20 Distalgesic tablets in association with another central nervous system depressant will succumb unless resuscitation facilities are available. Hence the term "potential death rate." The rationale of this analysis is fully detailed in the paper.

We also feel obliged to comment on the injunction of $\mathrm{Mr}$ Dwyer and $\mathrm{Dr}$ Jones to avoid prescribing Distalgesic to alcoholics. Given that alcoholism is frequently a carefully concealed problem, the superficial common sense of this statement has nevertheless little bearing on the reality of GP prescribing.

Needless to say, we welcome their quest for dispassionate and objective data on this difficult problem. By carrying out the first tota 
community survey of Distalgesic poisoning and thereby illustrating its true morbidity, mortality, and prevalence, we hope to have contributed to this end. Our results clearly indicate that in our area Distalgesic is now the principal cause of self-poisoning fatalities. This finding must surely be viewed in conjunction with the fact that there remains no conclusive evidence that this drug has any superior analgesic efficacy when compared with other manifestly less dangerous alternatives.

ROBERT J YOUNG

Diabetic Department,

Royal Infirmary,

A A H Lawson

Milesmark Hospital

Dunfermline KY129NR

\section{Addiction to Distalgesic (dextropropoxyphene)}

SIR,-I am frankly astounded to read that a patient with addiction to dextropropoxyphene was given methadone during the withdrawal phase, as reported by Dr Robert Wall and others (17 May, p 1213). Why could the patient not have been allowed to withdraw from the dextropropoxyphene without complicating matters by using another, even more highly addictive, substance?

Our "detox" unit in this city treats many cases of withdrawal from diazepam, heroin, dextropropoxyphene, etc; and it has rarely been shown necessary to complicate the picture or postpone the suffering by adding other drugs.

\footnotetext{
Drug and Alcohol Rehabilitation Society,

British Columbia V8W 1 M8,

Canada
}

** We sent this letter to Dr Wall, whose reply

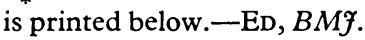

SIR,-Dr Mellor raises an interesting point concerning the use of substitute narcotics in the treatment of opiate-type dependency. Methadone is now widely used to deal with the abstinence symptoms of opiate withdrawal. Dextropropoxyphene produces dependency of this type whose severity is reflected in the amount consumed and length of time of abuse. Our patient had attempted many times to withdraw from Distalgesic. She had tried sudden and gradual withdrawal without success. There was some concern about the abnormal findings in liver function tests and subsequent liver biopsy. These were no doubt due to paracetamol toxicity and made it unwise to use Distalgesic on a reducing scale to effect withdrawal.

This patient had undoubted dependency and proved inability to curtail her abuse. In order to ensure her compliance in a treatment programme she was placed on low and diminishing doses of methadone for a limited period of time and under strict clinical supervision. As was to be expected, the small dose of methadone ameliorated her withdrawal symptoms and ensured her co-operation in the early stages of treatment, which are often distressing to the patient. During several months of outpatient follow-up she did not resort to abusing Distalgesic or any other drug and she was discharged from this unit.
The point here is that sudden withdrawal may be effective in treating true addiction in highly motivated patients with mild-tomoderate dependency. However, there is a risk that treatment will be stopped and abuse resumed if the abstinence symptoms experienced are deemed by the patient to be too distressing. Methadone is of lower addictive potential than most other narcotic drugs hence its use in treating opiate-type dependency. The dose used in this case was at least half that commonly used in effecting opiate withdrawal, was given on a rapidly reducing schedule, and was given for a very short period of time. The risks of developing dependency on methadone were therefore negligible.

$$
\begin{aligned}
& \text { Regional Addiction Treatment } \\
& \text { Unit, } \\
& \text { All Saints Hospital, } \\
& \text { Birmingham B18 5SD }
\end{aligned}
$$

\section{Adverse reactions to $\mathrm{D}$-penicillamine after gold toxicity}

SIR,-We were interested to read the article by Dr M J Dodd and his colleagues on adverse reactions to $\mathrm{D}$-penicillamine after gold toxicity (21 June, p 1498).

We have looked at our own figures for patients developing gold toxicity and then starting treatment with penicillamine. Out of a total of 26 patients, 13 started penicillamine within six months of stopping gold therapy. Only one of these patients developed a reaction while on penicillamine (rash with gold and thrombocytopenia with penicillamine). The other 13 patients started penicillamine six months or more after stopping gold and four developed an adverse reaction.

The total incidence of adverse reactions $(5 / 26)$ compares with an incidence of $8 / 44$ for our patients on penicillamine without prior gold therapy. We conclude from our figures, firstly, that there is no increased incidence of adverse reactions to penicillamine in patients who have had an adverse reaction to gold and, secondly, that there is no increased risk if the penicillamine is started within six months of stopping gold therapy.

A detailed table is available on request.

P J SMITH

Rheumatology Unit,

Wrightington Hospital,

W R SWINBURN

Prescribing psychoactive drugs to addicts

SIR,-Dr Thomas Bewley in his article (16 August, p 497) draws attention to the need for doctors in private practice to be particularly aware of the pitfalls which may occur in respect of prescribing psychoactive drugs to addicts. However, I believe that I speak for the main body of private physicians when I say that we are intensely aware of these problemsto such an extent that for most of us the situation does not arise in the context of agents which are controlled under the Misuse of Drugs Act.

What presents far greater difficulty in everyday practice is the problem of patients who request prescriptions of certain other drugs, including appetite suppressants such as diethylpropion and other types of sedatives quite apart from the barbiturate group. Indeed, after some three years in full-time private practice I have become so concerned about this that I have made some early moves to develop a private doctor's forum whereby such problems could be mutually discussed; thus I could envisage the establishment of some form of register whereby that all-toofamiliar patient could be confidentially registered and thus identified early on presentation. All of us must have had the suspicion that there is a nucleus of such drug abusers who will foist themselves on one physician after another, procuring psychoactive drugs and changing doctors as soon as the going gets rough.

Certainly more open discussion and widespread education of doctors concerning the best ways of handling patients at this particular interface must result in the profession acting with united policy to serve the best interests of the patient who behaves in such a manner; and, while there unfortunately will always be those who will compromise the professional ethic for fiscal reasons, a forum such as I have proposed should also serve to minimise any aspersions that private doctors in general are a soft touch for whatever drug a patient may ordain for himself.

London SW3 1RH

MARTIN SCURR

\section{Disturbed behaviour induced by}

high-dose antipsychotic drugs

SIR, - We read with interest the report by Dr T R E Barnes and P K Bridges on disturbed behaviour induced by high-dose antipsychotic drugs (26 July, p 274). We would like to make the following comments.

(1) The disturbed behaviour described in the three reported cases was characterised by excitement, restlessness, and aggression. The behaviour is more likely to be due to akathisia, which is known to occur in patients on high doses of antipsychotics, than to a relapse of these patients' schizophrenic illness. The authors themselves stress that the symptoms were "atypical for the patient."

(2) Two of the patients reported improved on reduction of the dose of antipsychotics and one of them needed big doses of antiParkinsonian medication throughout. The third patient settled down slowly as the blood level of flupenthixol gradually decreased and the drug was replaced with haloperidol, which probably acts on a different site. These observations support our claim that the behaviour described is consistent with a known side effect, akathisia, and not with a relapse of the schizophrenic illness.

(3) The first explanation suggested by Drs Barnes and Bridges, enhancement of the presynaptic release of dopamine, may explain the development of akathisia on high doses of antipsychotics rather than the recurrence of schizophrenia.

(4) As to the second explanation, anticholinergic toxic psychosis, the fact that in none of the three cases reported was there any mention of impairment of consciousness makes this explanation very unlikely.

(5) The development of restlessness, excitement, and aggression on high doses of antipsychotics is by no means a rare conditon. We can recall at least two patients in the past six months in whom similar symptoms were 